\title{
Positive impact of COVID-19 on career choice in pediatric medical students: a longitudinal study
}

\author{
Liyuan $\mathrm{Hu}^{1,2 \#}$, Hao $\mathrm{Wu}^{1 \#}$, Wenhao Zhou ${ }^{1,2}$, Jianqing Shen ${ }^{1}$, Wenwei Qiu ${ }^{1}$, Ruo Zhang ${ }^{1}$, Jingyan $\mathrm{Wu}^{1}$, \\ Yiming Chai ${ }^{1,3}$
}

${ }^{1}$ Department of Education and Training, ${ }^{2}$ Department of Neonatology, ${ }^{3}$ Department of Neurology, Children's Hospital of Fudan University, Shanghai, China

Contributions: (I) Conception and design: J Wu, Y Chai; (II) Administrative support: W Zhou; (III) Provision of study materials or patients: W Qiu, R Zhang, J Shen; (IV) Collection and assembly of data: All authors; (V) Data analysis and interpretation: L Hu, H Wu, J Wu, Y Chai; (VI) Manuscript writing: All authors; (VII) Final approval of manuscript: All authors.

"These authors contributed equally to this work.

Correspondence to: Jingyan Wu. Department of Education and Training, Children's Hospital of Fudan University, 399 Wanyuan Road, Minhang District, Shanghai, China. Email: wujingyan@fudan.edu.cn; Yiming Chai. Department of Education and Training, Children’s Hospital of Fudan University, 399 Wanyuan Road, Minhang District, Shanghai, China. Email: acyimm@hotmail.com.

Background: On March 11 ${ }^{\text {th }}, 2020$, the WHO made the assessment that coronavirus disease 2019 (COVID-19) could be characterized as a pandemic. Medical students experienced a greater degree of anxiety and psychological stress than during previous pandemics. Negative emotions were related to decreased medical career interest, increased career choice regret and dropout rates in medical students, which affected academic and professional development. The goal of this study was to investigate the impact of the current COVID-19 outbreak on the career preferences of pediatric medical students and to explore the underlying factors contributing to it.

Methods: A prospective, longitudinal study was conducted among all 120 pediatric medical students from Shanghai Medical College of Fudan University on November 23 ${ }^{\text {rd }}, 2019$, and February $21^{\text {st }}, 2020$ using a 7-item online questionnaire about career choice.

Results: A total of 106 (41 male and 65 female) students with a mean age of 21 years consented to participate in this study. The response rate was $100 \%$ in November 2019 and $98.1 \%$ in February 2020. Since the outbreak, career choices to practice medicine or pediatrics did not drop significantly, decreasing by only $4.3 \%$ and $2.2 \%$, respectively. There was a positive impact of the COVID-19 outbreak on strengthening $66.7 \%$ of students' beliefs and choices to become good pediatricians $(\mathrm{P}<0.001)$. Only 14 students $(13.5 \%)$ thought that COVID-19 had a negative impact on their career choices, but the majority of them were in the $3^{\text {rd }}(28.6 \%)$ and $4^{\text {th }}(64.3 \%)$ years of medical education and had insufficient knowledge about the hospital environment and clinics.

Conclusions: The outbreak of COVID-19 might have an overall positive impact on career choice by strengthening students' belief and choice to become good doctors and may decrease the choice regret and drop rates of the next generation of doctors. Special attention should be paid to students with insufficient clinical experience. Good protection for students, sharing outstanding stories regarding fighting the pandemic, and innovations of needs-based curriculum could be helpful during this pandemic. Future studies are warranted to confirm these findings.

Keywords: COVID-19; China; career choice; medical student; pediatrics

Submitted Mar 16, 2020. Accepted for publication Jun 22, 2020.

doi: $10.21037 /$ tp-20-100

View this article at: http://dx.doi.org/10.21037/tp-20-100 


\section{Introduction}

The current outbreak of coronavirus disease 2019 (COVID-19) was an emerging global problem. The World Health Organization (WHO) declared COVID-19 a Public Health Emergency of International Concern (PHEIC) at the end of January 2020 (1). The COVID-19 virus infects people of all ages and rapidly spread globally. On 11 March 2020, the number of cases of COVID-19 outside China had increased 13-fold, and the number of affected countries tripled in two weeks, overwhelming global public health services. At the time of writing, there were more than 118,000 cases in 114 countries and 4,291 people had lost their lives, with a mortality rate of $3.64 \%$ (2). Therefore, the WHO made the assessment that COVID-19 could be characterized as a pandemic (3).

The rates of healthcare personnel (HCP)-related infection in outbreaks of infectious disease are high. The number of reported cases of COVID-19 in Chinese HCP had increased to 1,716 , including 5 deaths, among a total of 72,314 case records on 11 February 2020 (4). The HCP-related infection rate was reported to be approximately $1 \%$ to $27 \%$ for the Middle East respiratory syndrome coronavirus, $2.5 \%$ to $12 \%$ for the Ebola virus, and $11 \%$ to $57 \%$ for the severe acute respiratory syndrome (SARS) virus (5), with adverse psychological and occupational impacts on HCP and medical students, such as fear and anxiety (6-8).

A study showed that the global prevalence rate of anxiety among medical students was $33.8 \%$, with the highest prevalence in the Middle East and Asia [9]. Evidently, negative emotions are related to decreased medical career interest, increased career choice regret and dropout rates in medical students and affect academic and professional development (9-12).

To the best of our knowledge, there has been no longitudinal study investigating the impact of the COVID-19 outbreak on the career choice of medical students. We conducted this study with the aims of bridging this gap, identifying underlying factors that contribute to that impact, and providing evidence for needs-based curriculum reform to help increase the number of medical doctors in various specialties, including pediatrics. We present the following article in accordance with the SURGE reporting checklist (available at http://dx.doi.org/10.21037/ tp-20-100).

\section{Methods}

\section{Ethical approval}

The study was conducted in accordance with the Declaration of Helsinki. The study was approved by the Research Ethics Committee of the Children's Hospital of Fudan University (No.: 2020-300). Informed verbal consent was required from all the participants.

\section{Subject selection}

A prospective, longitudinal observational study was conducted among all 120 pediatric medical students from Shanghai Medical College of Fudan University. The students were asked to complete an online 7-item questionnaire about their career choices. Fourteen students who did not consent to participate were excluded. A total of 106 pediatric medical students were included in this study, representing $88.3 \%$ of all targeted medical students.

\section{Data collection}

An anonymous online electronic questionnaire was sent to the 106 study participants on November $23^{\text {rd }}, 2019$, and February $21^{\text {st }}, 2020$, representing choices before and after the outbreak of COVID-19. This survey collected information including gender, year of admission to the college, province of permanent residency, career choice of being a doctor/pediatrician/not determined yet/no medicine, reason for that choice, and anxiety at the time of the survey using a 10-point self-assessment scale (anxiety levels were proportional to the points from ' 0 ' to ' 9 ', with ' 0 ' representing no anxiety and 9 representing the highest degree of anxiety) after the outbreak of COVID-19.

\section{Statistical analysis}

Continuous variables are expressed as the means \pm standard deviations. Categorical variables are presented as percentages. Differences in anxiety scores among Chinese pediatric medical students according to gender, age, and career choice were evaluated using $t$-tests. Univariate analyses of categorical data were conducted with chisquare and Fisher exact tests. Differences were considered statistically significant with a two-tailed $\mathrm{P}$ value $<0.05$. The 




Figure 1 Participant flow.

Table 1 Baseline characteristics of the enrolled medical students*

\begin{tabular}{lcc}
\hline Characteristics & Before COVID-19 (N=106) & After COVID-19 (N=104) \\
\hline Age, year & $21.28 \pm 0.97$ & $21.28 \pm 0.96$ \\
Female sex, no./total (\%) & $65 / 106(61.3)$ & $63 / 104(60.6)$ \\
Grade 2015 & $7 / 10(70.0)$ & $7 / 10(70.0)$ \\
Grade $2016^{\S}$ & $22 / 37(59.5)$ & $21 / 36(58.3)$ \\
Grade $2017^{\Uparrow}$ & $17 / 30(56.7)$ & $17 / 30(56.7)$ \\
Grade 2018 & $19 / 29(65.5)$ & $18 / 28(64.3)$ \\
Students involved in clinical rotation, no./total $(\%)^{\dagger}$ & $47 / 106(44.3)$ & $46 / 104(44.2)$ \\
\hline
\end{tabular}

*, Plus-minus values are means \pm SD. There were no significant differences $(P \geq 0.05)$ between the two groups for baseline variables; ${ }^{\ddagger}$, Grade 2015 students were in the fifth year and had clerkship training in hospitals; ${ }^{\S}$, Grade 2016 students were in the fourth year and had observational rotation in hospitals; ", Grade 2017 and 2018 students were not involved in clinical rotation; Clinical rotations were withheld since the end of January 2020. ${ }^{\dagger}$, Included students from grade 2015 and grade 2016.

analysis was performed using IBM SPSS 25.0.

\section{Results}

\section{Participants and their career choices in medicine and pediatrics}

Figure 1 shows the participant flow. The response rate of the first survey in November 2019 was $100 \%$. Two female students failed to answer the questionnaire on 21 February 2020 , resulting in a response rate of $98.1 \%$.

Table 1 shows the baseline characteristics of the enrolled participants. There were a total of 41 male and 65 female participants from grade 2015 to grade 2018 with a mean age of 21 years enrolled in this study. None of the students originally came from Hubei Province or had relatives infected with COVID-19 at the time of the survey. The percentage of male participants $(38.7 \%)$ was lower than that of female participants $(61.3 \%)$.

Table 2 shows the participants' career choices before and after the COVID-19 outbreak. Before the outbreak, the career choices of practicing pediatrics, medicine but not pediatrics and no medicine were reported by $39.6 \%, 33.0 \%$ and $1.9 \%$ of the students, respectively. Since the outbreak of coronavirus, the career choices of practicing pediatrics and medicine but not pediatrics have decreased by $4.3 \%$ and $2.2 \%$, respectively, with a mild increase in the preference for non-medicine-related careers by $0.9 \%$. Nevertheless, no statistical correlation was identified among gender, experience of clinical rotation and different career choices.

\section{Characteristics of the impact on career choice after the outbreak}

Table 3 shows the distribution of age, gender and career 
Table 2 Participants' career choices before and after the COVID-19 outbreak

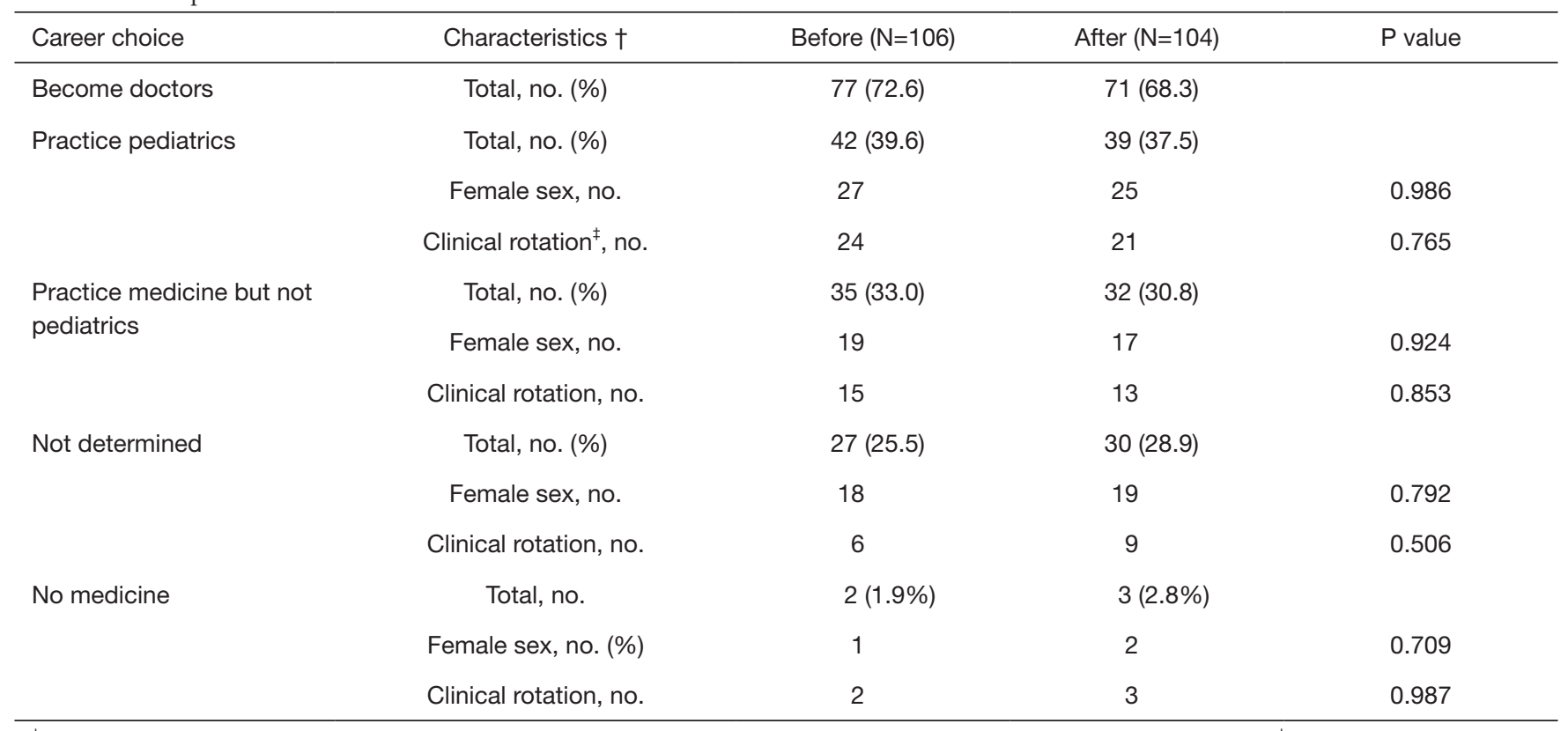

${ }^{\dagger}$, there was no significant difference $(\mathrm{P}=0.9)$ in the proportion of different career choices between the two groups; ${ }^{\ddagger}$, this included students only from grades 2015 and 2016.

Table 3 Distribution of age, gender and career choice by the nature of different impacts

\begin{tabular}{|c|c|c|c|c|}
\hline Group & Positive ( $\mathrm{N}=49)$ & Negative $(\mathrm{N}=14)$ & No impact $(\mathrm{N}=41)$ & $P$ value \\
\hline \multicolumn{5}{|l|}{ Gender } \\
\hline Male & 21 & 6 & 14 & \multirow[t]{2}{*}{0.681} \\
\hline Female & 28 & 8 & 27 & \\
\hline Pediatrics & 26 & 3 & 10 & \multirow[t]{3}{*}{$<0.001$} \\
\hline $\begin{array}{l}\text { Medicine but not } \\
\text { pediatrics }\end{array}$ & 17 & 6 & 9 & \\
\hline Not determined & 6 & 4 & 20 & \\
\hline
\end{tabular}

choice by the nature of different impacts (positive, negative and no impact) of the outbreak. There was no significant difference in age $(\mathrm{P}=0.474)$ or gender group $(\mathrm{P}=0.681)$.

Forty-one students $(41 / 104,39.4 \%)$ thought the COVID-19 outbreak had no impact on their career choices. Forty-nine students $(49 / 104,47.1 \%)$ thought it had a positive impact. Among them, 43 students confirmed the decision to become a good doctor, and 6 students were considering becoming doctors. This positive effect was more pronounced among 39 students $(26 / 39,66.7 \%)$ who wanted to practice pediatrics. The outbreak positively strengthened most pediatric medical students' belief in practicing medicine or pediatrics $(\mathrm{P}<0.001)$. With respect to the reasons, the majority of students thought it was a great honor to become doctors to save lives despite the high work pressure and intensity.

Only 14 students (13.5\%) thought that COVID-19 had 


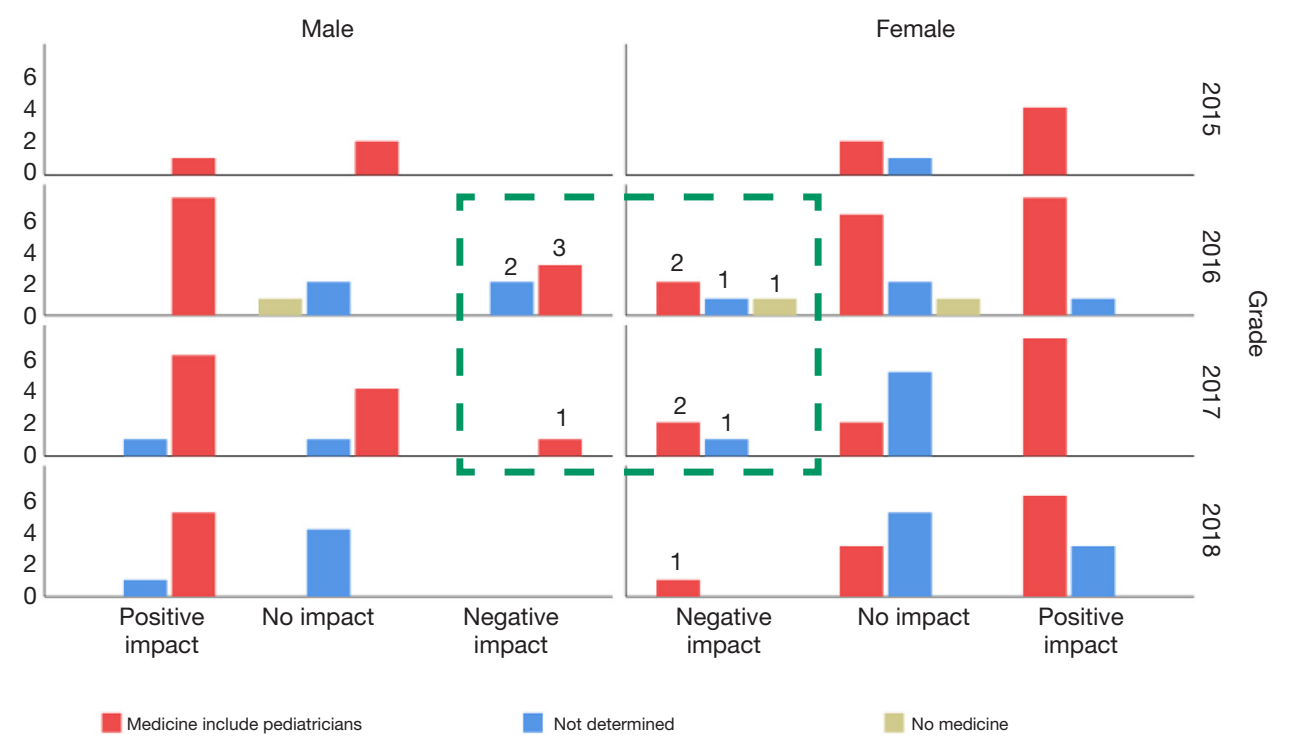

Figure 2 The distribution of gender, grade and career choice by the nature of different impacts (positive, negative and no impact) of the outbreak. The red, blue and brown bars represent career choices of practicing medicine (include pediatrics), not determined and no medicine. The $\mathrm{x}$ axis represents the nature of the impact and is distributed by gender. The $\mathrm{y}$ axis represents the numbers of students and is distributed by different grades. The green dotted box highlights the characteristic of students who experienced a negative impact of COVID-19.

a negative impact on their career choices. Nine students felt worried, and two students felt confused about practicing medicine and would probably change their mind after graduation. One student who initially wanted to be a doctor decided not to practice medicine at the time of the survey. The reasons for these choices included high-intensity clinical work, low-paying salaries and fear of not being able to save patients' lives.

It is worth mentioning that 9 of the 14 students (64.3\%) were from grade 2016 and were in the fourth year of undergraduate medical education; they had undergone observational rotation but had not started clerkship training in clinical settings. Four of them (28.6\%) were from grade 2017 and were in the third year of undergraduate medical education; they had just started clinical courses but were not involved in clinical rotations (highlighted in the green dotted box in Figure 2).

\section{Anxiety status in different career choice groups since the outbreak}

Pediatric medical students were asked to score their anxiety levels after the outbreak on a 10-point self-assessment scale.
The anxiety level is proportional to scores from ' 0 ' to ' 9 '. Zero represents no anxious status, and 9 equals the highest level of anxiety. The participants' mean anxiety score was 3.0 \pm 2.0 . The mean anxiety scores for grades 2015,2016 , 2017 and 2018 were $2.4 \pm 1.3,3.0 \pm 2.3,3.4 \pm 2.1$, and $2.9 \pm 1.8$, respectively. No significant differences were found among genders $(\mathrm{P}=0.276)$ and grades $(\mathrm{P}=0.531)$. Figure 3 illustrates the distribution of the anxiety scores of 104 pediatric medical students. Since the outbreak of COVID-19, 13 students (12.5\%) did not feel anxious, 51 (49\%) scored less than 3, $34(32.7 \%)$ scored between 4 and 6 , and only 6 $(5.8 \%)$ scored more than 7 .

Figure 4 presents the anxiety scores in different career choice groups after the outbreak. The mean anxiety scores ranged from $3.5 \pm 1.9$ in the 'pediatrics' group to $1.0 \pm 1.0$ in the 'no medicine' group. The mean anxiety scores of students who planned to practice pediatrics were significantly higher than those of students not interested in medicine $(\mathrm{P}=0.034)$. The majority of them were anxious about the severity of the disease, cared about the patients and doctors infected in Wuhan Province and worried about whether they could be excellent doctors under similar circumstances. 


\section{Discussion} The significance of enrolling pediatric medical students
and investigating changes in career choice in this study

Between 1999 and 2016, medical students in China started

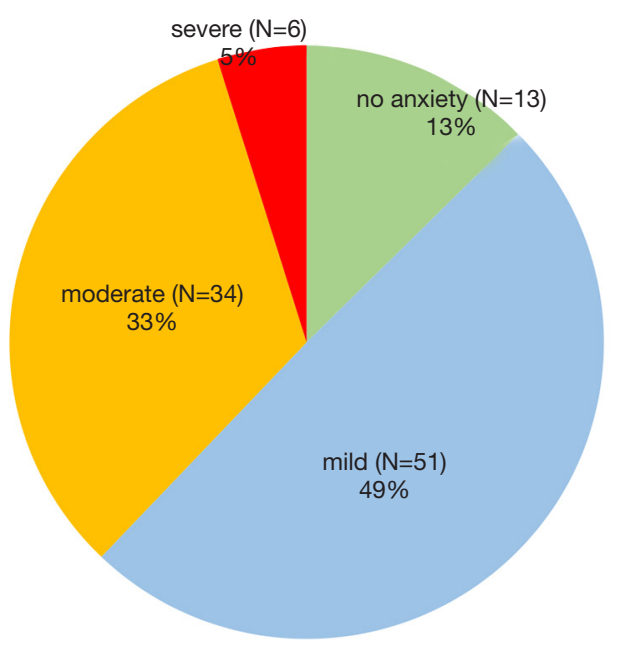

Figure 3 Distribution of anxiety scores of 104 pediatric medical students. No anxiety refers to an anxiety score equal to 0 ; mild anxiety refers to scores from 1 to 3 ; moderate anxiety refers to scores from 4 to 6 ; severe anxiety refers to scores greater than 7 . their pediatric residency program only after finishing 5-year general undergraduate medical education. They had little knowledge about pediatrics until they started residency training in the hospital. Their career choices were often influenced by the experience of working in a hospital. Motivational factors and career interest influence students' intentions to make future professional choices.

In comparison with other specialties, Chinese pediatricians' job satisfaction is diminishing because of their relatively low salary, high workload, and intense patient-physician relationship (13). The dropout rate of pediatricians is $12.6 \%$ (14). Applications for pediatric posts from medical students are decreasing as well. A survey among first-year medical students in China, Malaysia and regions of South Asia revealed that only $1.1 \%$ had an interest in pediatric professions (15).

The shortage of pediatricians in China is alarming (16). According to a recent national survey, China has a large population of 279 million children and faces a growing pediatric workforce shortage. A recent national survey indicates that the gap to reach the target of 0.69 pediatricians per 1,000 children by 2020 is approximately 90,000 pediatricians (14). In 2016, the Ministry of Education relaunched the admission policy of 5-year undergraduate medicine education in pediatric

$60.0 \%$

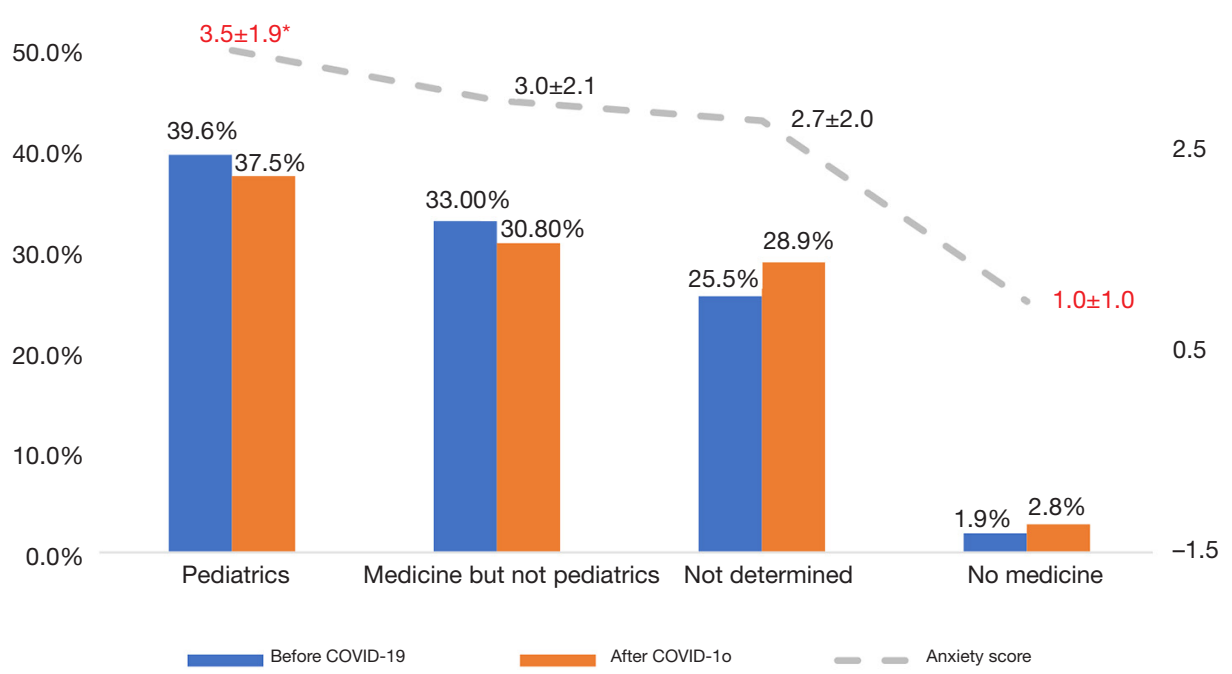

Figure 4 Anxiety scores in different career choice groups after COVID-19 outbreak. Blue and orange bars represent career choices before and after the outbreak of COVID-19. Grey dotted line represents the trend of average anxiety among different career choice groups after the outbreak. * shows that students who planned to practice pediatrics had significantly higher average anxiety scores than those who did not plan to become doctors $(\mathrm{P}=0.034)$. 
specialization, mainly to recruit students with high aspirations to practice pediatrics (17), to better meet the demand for nationwide healthcare services for children.

This study was part of the project "Establish the penetrative training mode of pediatric humanism in stage center", which was funded by the Clinical Science and Technology Innovation Project of Shanghai Shenkang Hospital Development. Among the 120 pediatric medical students of all grades from Fudan University, 106 students consented to participate in this study. The results can represent the majority of the study objects. In light of the promotion of pediatricians as a national priority in China, the intent of this project is to better understand the challenges students face by using career choice as an indicator and comparing the changes of career preferences during 5-year undergraduate education, to check for goodness-of-fit with students' personal goals and aspirations, to efficiently cultivate their career empathy by appropriate intervention and to provide evidence for needsbased curriculum reform.

This unique situation of having a large cohort of pediatric medical students affords the opportunity to make a prospective comparison of career choices before and after the coronavirus pandemic outbreak, and the high response rate of $98.1 \%(104 / 106)$ can effectively avoid bias to some extent.

A shortage of the health care workforce is a global problem. The clock is ticking as the number of reported cases of COVID-19 in other countries has climbed dramatically. Despite cultural differences, our findings might be helpful to draw attention to the specific impact of this crisis on medical students' mental health and career preferences to help increase the numbers of medical doctors in various specialties, including pediatrics, by working on needs-based curriculum reform.

\section{Explanation of the overall positive impact of COVID-19 on the career choices of pediatric medical students}

Compared to career choices before the outbreak, there was a mild decline in career preferences for medicine or pediatrics, from $72.6 \%$ to $68.3 \%$ and from $39.6 \%$ to $37.5 \%$, respectively. No difference was found between male and female students. It is worth mentioning that the percentage of preference for pediatrics in our study was much higher than that of $1.1 \%$ reported by Kumar et al. (15).

One of the explanations for this finding might be correlated with students' intrinsic interests in pediatrics before admission to the university. In addition, although it was beyond the scope of this study, we would like to mention four major innovations to efficiently maintain students' interest in the pediatric profession, to help them understand the meaning of being a pediatrician and to increase the retention rate of certified doctors in pediatrics. Our innovations include (I) a dual-mentor system focusing on students' emotional health and professional competencies, (II) a hybrid teaching mode of small private online courses, flipped classrooms, problem-based learning and simulation-based skill training, (III) early exposure to pediatric clinical settings including volunteer activities and observational rotations, and (IV) the construction of a well-rounded training system for teachers in pediatrics to guarantee persistent innovations of needs-based curriculum reform.

The Children's Hospital of Fudan University is one of the top 3 pediatric specialized hospitals in China and is a key teaching hospital of Fudan University. It is the only designated COVID-19 hospital in Shanghai where suspected pediatric cases were sent for screening and isolation. It is worth noting that at the height of the SARS outbreak, a significantly greater degree of anxiety and psychological stress was noted in medical students $(8,18,19)$. Mental health problems had a positive correlation with negative life events and neuroticism.

In terms of the nature of this outbreak on students' career choice, we were surprised but glad to see the positive impact of this pandemic that strengthened two-thirds (66.7\%) of pediatric medical students' belief and choice in practicing medicine or pediatrics after graduation. We anticipated that this positive impact might be helpful to decrease the choice regret and drop rates of the next generation of doctors because interest and belief play an important role in persisting in one's career. The underlying causes of this phenomenon are described below.

The National Health Commission has released guidelines for local authorities to promote psychological crisis intervention for patients, medical personnel, and people under medical observation during this outbreak (20). In response to the COVID-19 outbreak, pediatric medical students were asked to take distance learning programs at home. This approach could effectively avoid disruption of education, provide social care and interaction through the internet, avoid activities in a high-risk hospital environment, prevent viral exposure and prevent anxiety about being infected. This could be a reason for the relatively low anxiety scores of $3.0 \pm 2.0$ in our study after the outbreak. 
Moreover, physicians and scientists from Fudan University have shown very positive images by actively becoming involved in scientific research and clinical work during this outbreak. The first sequence of $2019-\mathrm{nCoV}$ was identified by scientists at Fudan University, Shanghai (21). Thousands of medical workers from the affiliated hospitals of Fudan University went to Hubei Province to provide medical assistance. With respect to pediatric patients, the number of reported cases of COVID-19 in children less than 10 years old gradually increased to 416 according to data from 11 February 2020 (4). Nine of 11 pediatric patients had been successfully discharged from the Children's Hospital of Fudan University. During a pandemic outbreak, medical students' excessive anxiety could be eased by abundant professional knowledge from hospitals and medical staff and a more realistic assessment of the virus risk (8).

When they were asked about the reasons for their career choice after the outbreak on 21 February 2020, the majority of them were anxious about the severity of the disease, cared about the patients and doctors infected in Wuhan Province and worried about whether they could be excellent doctors under similar circumstances. Empathy might be another contributor to this finding. Empathy is significantly associated with clinical and academic performance among students (22). Our curriculum includes early exposure to clinical pediatric training and a series of courses to promote professional competencies and communication skills, which has been proven to help students adopt the patient's perspective and gain a better understanding of the patient's situation, concerns, and feelings; thus, it may contribute to the development of higher sensitivity toward the patients, which could increase students' empathic ability (23).

Although only 14 students $(13.5 \%)$ thought that COVID-19 had a negative impact on their career choices, the majority of them were students in the $3^{\text {rd }}(28.6 \%)$ and $4^{\text {th }}(64.3 \%)$ years of medical education. These students did not have sufficient exposure to the hospital environment and were more vulnerable to changing their choices due to a lack of relevant health care knowledge. Mentors and supervisors should pay more attention to students with this knowledge background. Interventions should be applied to focus on their emotions and stress levels.

\section{Limitations}

The findings from this study should be interpreted in light of several limitations. First, all the participants were pediatric medical students from Fudan University in
Shanghai; therefore, they may not be representative of national responses. Future research should include other university populations of pediatric medical students. Second, although there was a high response rate in this study, we are unable to determine the characteristics of non-responders, which could result in selective bias. Third, the current classifications of career choices were relatively too large and did not investigate subspecialties such as respiratory medicine or intensive care medicine. Future studies should include those choices to give a full picture of the impact. Finally, the self-report survey may lead to response bias. Follow-up studies are required about the respondents' jobs after graduation and to obtain more comprehensive and objective results.

\section{Conclusions}

The outbreak of COVID-19 might have a positive impact on career choice by strengthening students' belief and choice to become good doctors and may decrease the choice regret and drop rates of the next generation of doctors. We acknowledge that our findings may not be generalizable to all countries because cultures and education systems vary. Good protection for students, sharing outstanding stories regarding fighting the pandemic, and innovations of needsbased curriculum would be helpful during this pandemic. Future studies are warranted to confirm this finding.

\section{Acknowledgments}

We would like to thank all the pediatric medical students who participated in this study and Shanghai College of Fudan University for their cooperation and kind support.

Funding: This work was supported by Shenkang Hospital Development, Shanghai government, grant number: SHDC12018623.

\section{Footnote}

Data Sharing Statement: Available at http://dx.doi. org/10.21037/tp-20-100

Peer Review File: Available at http://dx.doi.org/10.21037/tp20-100

Reporting Checklist: The authors have completed the SURGE reporting checklist. Available at http://dx.doi. org/10.21037/tp-20-100 
Conflicts of Interest: All authors have completed the ICMJE uniform disclosure form (available at http://dx.doi. org/10.21037/tp-20-100). The authors have no conflicts of interest to declare.

Ethical Statement: The authors are accountable for all aspects of the work in ensuring that questions related to the accuracy or integrity of any part of the work are appropriately investigated and resolved. The study was conducted in accordance with the Declaration of Helsinki. The study was approved by the Research Ethics Committee of the Children's Hospital of Fudan University (No.: 2020300). Informed verbal consent was required from all the participants.

Open Access Statement: This is an Open Access article distributed in accordance with the Creative Commons Attribution-NonCommercial-NoDerivs 4.0 International License (CC BY-NC-ND 4.0), which permits the noncommercial replication and distribution of the article with the strict proviso that no changes or edits are made and the original work is properly cited (including links to both the formal publication through the relevant DOI and the license). See: https://creativecommons.org/licenses/by-nc-nd/4.0/.

\section{References}

1. Available online: https://www.who.int/docs/default-source/ coronaviruse/situation-reports/20200131-sitrep-11-ncov. pdf?sfvrsn=de7c0f7_4

2. Available online: https://www.who.int/docs/default-source/ coronaviruse/situation-reports/20200311-sitrep-51covid-19.pdf?sfvrsn=1ba62e57_4

3. Available online: https://www.who.int/dg/speeches/detail/ who-director-general-s-opening-remarks-at-the-mediabriefing-on-covid-19---11-march-2020

4. Wu Z, McGoogan JM. Characteristics of and Important Lessons From the Coronavirus Disease 2019 (COVID-19) Outbreak in China: Summary of a Report of 72314 Cases From the Chinese Center for Disease Control and Prevention. JAMA 2020. doi: 10.1001/jama.2020.2648.

5. Suwantarat N, Apisarnthanarak A. Risks to healthcare workers with emerging diseases: lessons from MERSCoV, Ebola, SARS, and avian flu. Curr Opin Infect Dis 2015;28:349-61.

6. Bao Y, Sun YK, Meng SQ, et al. 2019-nCoV epidemic: address mental health care to empower society. Lancet 2020;395:e37-8.
7. Maunder R, Hunter J, Vincent L, et al. The immediate psychological and occupational impact of the 2003 SARS outbreak in a teaching hospital. CMAJ 2003;168:1245-51.

8. Loh LC, Ali AM, Ang TH, et al. Impact of a spreading epidemic on medical students. Malays J Med Sci 2006;13:30-6.

9. Quek TT, Tam WW, Tran BX, et al. The Global Prevalence of Anxiety Among Medical Students: A MetaAnalysis. Int J Environ Res Public Health 2019;16:2735.

10. Grace MK. Depressive symptoms, burnout, and declining medical career interest among undergraduate pre-medical students. Int J Med Educ 2018;9:302-8.

11. Tian L, Pu J, Liu Y, et al. Relationship between burnout and career choice regret among Chinese neurology postgraduates. BMC Med Educ 2019;19:162.

12. Dyrbye LN, Thomas MR, Shanafelt TD. Systematic review of depression, anxiety, and other indicators of psychological distress among U.S. and Canadian medical students. Acad Med 2006;81:354-73.

13. Hu KJ, Sun ZZ, Rui YJ, et al. Shortage of paediatricians in China. Lancet 2014;383:954.

14. Zhang Y, Huang L, Zhou X, et al. Characteristics and Workload of Pediatricians in China. Pediatrics 2019;144:e20183532.

15. Kumar A, Mitra K, Nagarajan S, et al. Factors influencing medical students' choice of future specialization in medical sciences: a cross-sectional questionnaire survey from medical schools in china, malaysia and regions of South asian association for regional cooperation. $\mathrm{N}$ Am J Med Sci 2014;6:119-25.

16. Hu Y, Xu J, Dong W, et al. Strategies to correct the shortage of paediatricians in China. Lancet 2018;392:385.

17. Available online: http://www.nhc.gov.cn/wjw/xwdt/201602 /1a3d60670b13416ca0b910c7e0629259.shtml

18. Main A, Zhou Q, Ma Y, et al. Relations of SARSrelated stressors and coping to Chinese college students' psychological adjustment during the 2003 Beijing SARS epidemic. J Couns Psychol 2011;58:410-23.

19. Wong JG, Cheung EP, Cheung V, et al. Psychological responses to the SARS outbreak in healthcare students in Hong Kong. Med Teach 2004;26:657-9.

20. National Health Commission of the People's Republic of China. Guideline for psychological crisis intervention during 2019-nCoV.Jan 26,2020. Available online: http:// www.nhc.gov.cn/jkj/s3577/202001/6adc08b966594253b2b 791be5c3b9467.shtml

21. Virological.org. Novel 2019 Coronavirus Genome. Available online: http://virological.org/t/novel-2019- 
coronavirus-genome/319

22. Wen D, Ma X, Li H, et al. Empathy in Chinese medical students: psychometric characteristics and differences by gender and year of medical education. BMC Med Educ

Cite this article as: $\mathrm{Hu} \mathrm{L}, \mathrm{Wu} \mathrm{H}$, Zhou W, Shen J, Qiu W, Zhang R, Wu J, Chai Y. Positive impact of COVID-19 on career choice in pediatric medical students: a Longitudinal Study. Transl Pediatr 2020;9(3):243-252. doi: 10.21037/tp-20-100
2013;13:130.

23. Sng G, Tung J, Ping YS, et al. Complex and novel determinants of empathy change in medical students. Korean J Med Educ 2016;28:67-78. 